九州大学学術情報リポジトリ

Kyushu University Institutional Repository

\title{
Development of Method for Measuring the Degree of Maceration of Soybean Fermented with
} Rhizopus

Manurukchinakorn, Supranee

Laboratory of Food Technology, Faculty of Agriculture, Kyushu University

Fujio, Yusaku

Laboratory of Food Technology, Faculty of Agriculture, Kyushu University

https://doi.org/10.5109/24148

出版情報：九州大学大学院農学研究院紀要. 41 (3/4)，pp.223-230，1997-03. Kyushu University バージョン：

権利関係 : 


\title{
Development of Method for Measuring the Degree of Maceration of Soybean Fermented with Rhizopus
}

\author{
Supranee Manurukchinakorn and Yusaku Fujio*
}

\author{
Laboratory of Food Technology, Faculty of Agriculture, \\ Kyushu University, Fukuoka 812-81, Japan \\ (Received October 1, 1996; Accepted December 17, 1996)
}

\begin{abstract}
The force-deformation curve of bulk-soybean fermented with Rhizopus could be described by an equation, $\mathrm{F}=\mathrm{C}(\Delta \varepsilon)^{\mathrm{n}}$. The degree of maceration of fermented soybean (a measure of softness) was estimated by the n-value of the power of the equation. The degree of maceration of fermented soybean depended on the Rhizopus strain used. Of the Rhizopus strains tested, Rhizopus oligosporus (TISTR 3001, known as a dominant tempeh processing strain) and Rhizopus sp. LKN (isolated from a tempeh starter) gave high degrees of maceration corresponding to $\mathrm{n}=1.3$ (initial value of 1.8) and 1.6 (initial value of 1.8) respectively, for $60 \mathrm{~h}$ of fermentation of raw soybeans at $30^{\circ} \mathrm{C}$. For sterilized soybeans, the Rhizopus oligosporus and Rhizopus sp. LKN gave n-values of 1.5 (initial value of 1.7) and 1.3 (initial value of 1.7) respectively, for $60 \mathrm{~h}$ of fermentation at $30^{\circ} \mathrm{C}$. N-values less than 1.5 were considered as indicating considerably high degrees of maceration.
\end{abstract}

\section{INTRODUCTION}

Legumes and grains fermented with microorganisms improve their nutritional values and digestibility as human food (Steinkraus, 1986). Some typical examples are tempeh (Indonesian-traditional fermented soybean (Hesseltine, 1965)) and natto (oriental fermented soybean (Hesseltine and Wang, 1967)). They are popular soybean food products fermented with Rhixopus oligosporus and Bacillus subtilis(natto), respectively. Boiled soybean (dehulled) as raw material is processed by fermentation with a suitable fungi or bacillus. During fermentation, the initially hard tissue of the soybean (cotyledon) converts to soft tissue by the maceration effects of microbial growth. As a result, the digestibility and nutritional values of the soybean improve with fermentation (Nout and Rombouts, 1990). Consequently, the degree of maceration (a measure of softness) of the fermented soybean becomes an important factor in food qualities, particularly in texture. Regarding the maceration degree of various solid foods until now, Kronenberg and Hang (1985) reported that textural measurements using puncture force may have valuable application in monitoring the degree of mycelial growth of fermentation in Meitauza, an indigenous Chinese food made from fermented okara (soymilk residue), used as a model system for solid state fermentation. Ariffin et al. (1994) reported an assessment of hyphal binding in tempeh by using an inverse-point bending test method. Regarding the development of the texturometer and the definition of hardness, Friedman et al. (1963) developed their own texturometer and defined the hardness. Brennan et al. (1970) and Kapsalis et al. (1970) also reported on the hardness

\footnotetext{
* Corresponding author
} 
by using General Foods Texturometer (the same texturometer as Friedman et al. (1963)). However, most specimens tested were the solid foods (a block of food) and there has been almost no research on the measuring method for bulk food (aggregate of small granules) such as fermented soybeans reported to date. Generally, the hardness or softness for the solid specimen was believed to be given in an equation, $F=C(D)^{n}$ in force F and deformation D relation (Peleg and Campanella, 1989).

This paper proposes to develop a method for measuring the degree of maceration of bulk soybeans fermented by Rhixopus strains.

\section{MATERIALS AND METHODS}

\section{Soybean}

Dehulled soybean (product of the USA) purchased from Kyuto Bussan Co. Ltd. (Fukuoka, Japan) was used as raw material in the fermentation.

\section{Microorganisms}

Seven Rhizopus strains, namely, four authentic Rhixopus strains (javanicus (IFO5442), oligosporus (TISTR3001), arrhizus (TISTR3247), sp. (UQM186F)) and three Rhiaopus isolates (sp. All and sp. F98 from fermented foods, sp. LKN from tempeh starter) were used for fermentation.

\section{Preparation of fermented soybean}

Fifty grams of soybeans was soaked in $3 \%$ lactic acid solution for $3 \mathrm{~h}$ at $30^{\circ} \mathrm{C}$ in a 500 $\mathrm{ml}$ Erlenmeyer-flask with cotton plug. After draining completely, this was used as the raw soybean specimen (moisture content was 60\%, wet basis). The sterilized soybean specimen was prepared by autoclaving the soaked raw soybeans at $121^{\circ} \mathrm{C}$ for $15 \mathrm{~min}$. The Rhizopus inocula were precultured in test tubes (PDA medium) for 7 days at $30^{\circ} \mathrm{C}$. Inoculation of Rhizopus into both the raw and sterilized soybeans was done by transferring spores and mycelia. Fermentation was carried out at $30^{\circ} \mathrm{C}$ for 24,36 and 60 h. The control soybean specimen was prepared following the same procedures without inoculation.

\section{Equipment}

A rheometer (R-UDJ-DM, Sun Kagaku Co. Ltd., Tokyo, Japan) was used to measure the relation between force and deformation. The modified measuring-cell (Fig. 1), made of acrylic resin, consisted of a cylindrical container $(3 \mathrm{~cm}$ in inner diameter and $10 \mathrm{~cm}$ in height) and a plunger $(2.8 \mathrm{~cm}$ in diameter and $2 \mathrm{~cm}$ in height). The bulk soybean (fermented or unfermented) specimen was first packed in the container to a height of 3 $\mathrm{cm}(13 \mathrm{~g}$, wet weight), unless stated otherwise, and compressed by the plunger at a constant speed of $2 \mathrm{~cm}$ per min up to a maximum force of $1 \mathrm{kgf}$. The force exerted on the plunger and the resultant plunger displacement were recorded on a recorder (Rika Denki Co. Ltd., Tokyo, Japan).

Twenty replicated measurements were conducted on raw and sterilized specimens, which were not inoculated, to estimate the error due to measuring techniques. The 


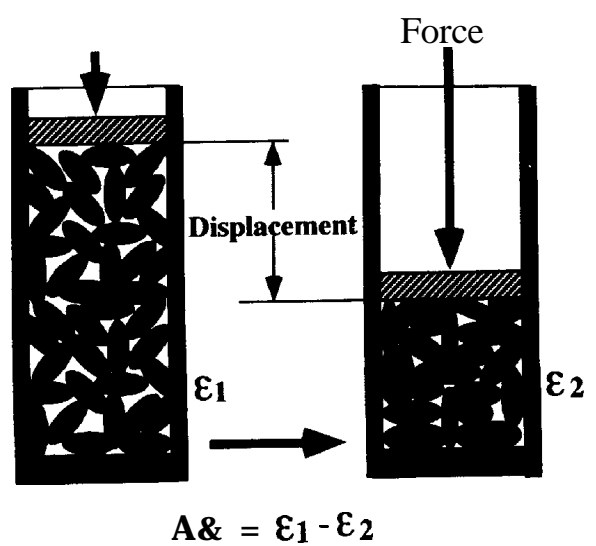

Fig. 1. Force-deformation measuring-cell. Symbol: $\Delta \varepsilon$, the porosity change

errors caused by differences in height of the packed specimen was estimated for packing heights of 3,5, 6 and $7 \mathrm{~cm}$. Data obtained were statistically analyzed for standard deviation at $95 \%$ confidence limit.

The moisture content of the raw and sterilized specimens were determined by drying soybeans at $105^{\circ} \mathrm{C}$ for $24 \mathrm{~h}$. The density of the soybean specimen was determined by putting $20 \mathrm{~g}$ of specimen in $60 \mathrm{ml}$ of salad oil and measuring the resultant volume increase. The porosity of the packed specimen was calculated from the soybean volume and the bulk volume of the packed soybeans. Initial porosity of the packed soybeans was 0.45 for all specimens.

\section{Force-deformation curve}

\section{RESULTS}

Fig. 2 (A, for raw soybean; B, for sterilized soybean) shows two typical forcedeformation curves. Though the curves obtained from different test specimens varied in shape, they generally exhibited common characteristics, some of which can be associated with descriptive textural parameters. There was an initial curved region as the soybean was packed into the measuring-cell, followed by more linear region as the specimen was compressed further.

\section{Reliability of data obtained}

Tables 1 and 2 summarize the effect of the packing height of the bulk soybean specimens on the measurement error. All values in Tables 1 and 2 were calculated from values from the starting position (at plunger position $=0$, displacement $=0$ ) to the final position (at a maximum plunger force of $1 \mathrm{kgf}$ ). The standard deviation of 20 replicated measurements at $95 \%$ confidence limit $(p<0.05)$ was lowest for a packing height of $3 \mathrm{~cm}$ and this height was used in all subsequent tests. The higher standard deviations for 


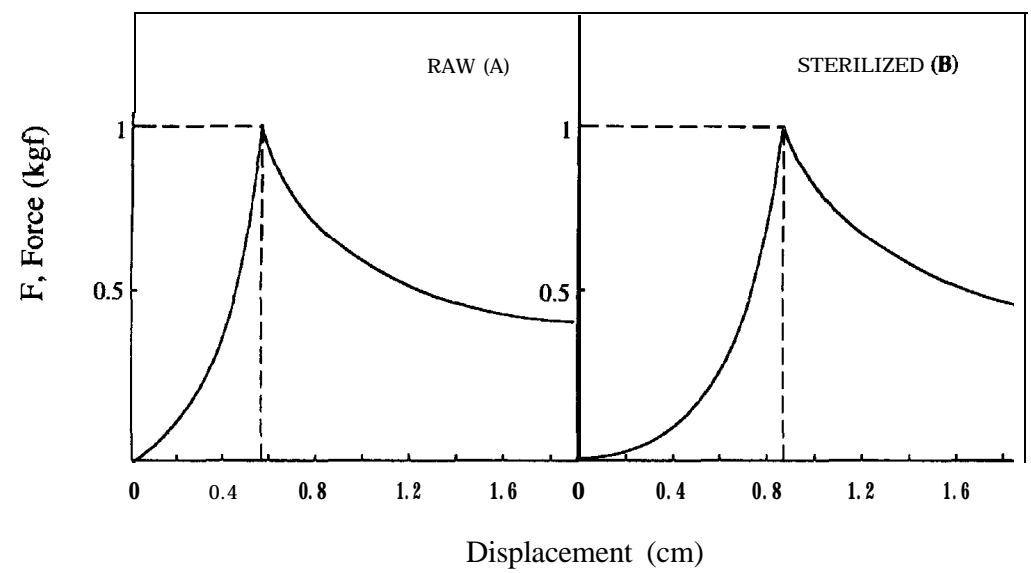

Fig. 2. Typical force-deformation curves obtained by a maximum compression force of $1 \mathrm{kgf}$ on the top surface of bulk soybean specimens. A, raw soybeans without fermentation; B, sterilized soybeans without fermentation.

Table 1. The error caused by difference in packing height of raw soybeans.

\begin{tabular}{ccc}
\hline $\begin{array}{c}\text { Sample amount } \\
(\mathrm{cm}(\mathrm{g}))\end{array}$ & $\begin{array}{c}\text { Maximum } \\
\text { displacement* } \\
(\mathrm{cm})\end{array}$ & $\begin{array}{c}\text { Std. Dev. } \\
(\mathrm{cm})\end{array}$ \\
\hline $3(13)$ & $0.508 \pm 0.013$ & 0.027 \\
$5(20)$ & $1.195 \pm 0.029$ & 0.065 \\
$6(25)$ & $0.869 \pm 0.028$ & 0.060 \\
$7(30)$ & $0.881 \pm 0.019$ & 0.060 \\
\hline
\end{tabular}

* a value at $95 \%$ confidence limit of an average from 20 replicates,

Table 2. The error caused by difference in packing height of sterilized soybeans.

\begin{tabular}{ccc}
\hline $\begin{array}{c}\text { Sample amount } \\
(\mathrm{cm}(\mathrm{g}))\end{array}$ & $\begin{array}{c}\text { Maximum } \\
\text { displacement* } \\
(\mathrm{cm})\end{array}$ & $\begin{array}{c}\text { Std. Dev. } \\
(\mathrm{cm})\end{array}$ \\
\hline $3(13)$ & $0.625 \pm 0.016$ & 0.034 \\
$5(20)$ & $1.118 \pm 0.036$ & 0.076 \\
$6(25)$ & $1.087 \pm 0.021$ & 0.060 \\
$7(30)$ & $0.993 \pm 0.026$ & 0.057
\end{tabular}

* a value at $95 \%$ confidence limit of an average from 20 replicates. 
higher packing heights could be due to greater lateral-pressure dispersion on the vertical sides of the measuring cell.

The reproducibility of the displacement values obtained for a packing height of $3 \mathrm{~cm}$ is shown in Tables 3 and 4 for raw and sterilized soybeans fermented for $48 \mathrm{~h}$, respectively.

Table 3. The maximum displacement in force-deformation curves of raw soybeans fermented with 7 strains of Rhizopus for $48 \mathrm{~h}$.

\begin{tabular}{ccc} 
Strain & $\begin{array}{c}\text { Displacement* } \\
(\mathrm{cm})\end{array}$ & $\begin{array}{c}\text { Std. Dev. } \\
(\mathrm{cm})\end{array}$ \\
\hline control & $0.559 \pm 0.012$ & 0.026 \\
IF05442 & $0.653 \pm 0.010$ & 0.022 \\
TISTR3247 & $0.583 \pm 0.013$ & 0.029 \\
A11 & $0.653 \pm 0.013$ & 0.027 \\
F98 & $0.712 \pm 0.025$ & 0.054 \\
UQM186F & $0.740 \pm 0.021$ & 0.044 \\
LKN & $0.779 \pm 0.019$ & 0.040 \\
TISTR3001 & $0.779 \pm 0.022$ & 0.048
\end{tabular}

* a value at $95 \%$ confidence limit of an average from 20 replicates.

Table 4. The maximum displacement in force-deformation curves of sterilized soybeans fermented with 7 strains of Rhizopus for $48 \mathrm{~h}$.

\begin{tabular}{ccc}
\hline Strain & $\begin{array}{c}\text { Displacement* } \\
(\mathrm{cm})\end{array}$ & $\begin{array}{c}\text { Std. Dev. } \\
(\mathrm{cm})\end{array}$ \\
control & $0.553 \pm 0.013$ & 0.028 \\
IF05442 & $0.766 \pm 0.025$ & 0.054 \\
TISTR3247 & $0.663 \pm 0.015$ & 0.032 \\
A11 & $0.741 \pm 0.019$ & 0.042 \\
F98 & $0.875 \pm 0.014$ & 0.029 \\
UQM186F & $0.930 \pm 0.025$ & 0.053 \\
LKN & $0.962 \pm 0.022$ & 0.048 \\
TISTR3001 & $0.963 \pm 0.024$ & 0.051 \\
\hline
\end{tabular}

* a value at $95 \%$ confidence limit of an average from 20 replicates. 


\section{Degree of maceration of fermented soybean}

The relation between the force and the deformation of solid specimen is commonly described by an equation, $\mathrm{F}=\mathrm{C}(\mathrm{D})^{\mathrm{n}}$. Assuming that the deformation (D) corresponding to the displacement of solid specimen can be replaced with the porosity change $(\Delta \varepsilon)$ for bulk specimen, the relation between the exerted force and the porosity change of the bulk specimen may have conformed to the equation:

$$
\begin{array}{ll} 
& \mathrm{F}=\mathrm{C}(\Delta \varepsilon)^{\mathrm{n}} \\
\text { where } & \mathrm{F} ; \text { loading force }(\mathrm{kgf}) \\
\mathrm{C} ; \text { arbitrary coefficient }(\mathrm{kgf}) \\
\Delta \varepsilon ; \text { changes in porosity from the initial value }(-) \\
\mathrm{n} ; \text { power coefficient }(-)
\end{array}
$$

Equation (1) can be transformed to

$$
\log \mathrm{F}=\log \mathrm{C}+\mathrm{n} \cdot \log \Delta \varepsilon
$$

A plot of $\log F$ versus $\log \Delta \varepsilon$ in the equation (2) should yield a straight line if the equation 2 is applicable. Figs. 3 and 4 show typical logarithmic plots of force (F) and porosity change $(\Delta \varepsilon)$ for Rhixopus oligosporus TISTR 3001 and Rhizopus sp. LKN fermentation, respectively. The straight lines were recognized, thus, equation (1) is applicable to force-deformation relation of the bulk specimen. Table 5 summarizes the $\mathrm{n}$ - and $\mathrm{C}$ values obtained from the slope of each line and the intercept on the y-axis, respectively. The n-value may be characterized as the degree of maceration depending on Rhixopus strains tested. Small $\mathrm{n}$-values were interpreted as indicating high maceration effects by the fermentation with Rhixopus tested. The variation in n-values (Table 5) may be caused by differences in the maceration capabilities of the different Rhixopus strains tested. Rhizopus strains giving small n-values may secrete soybean macerating-enzymes

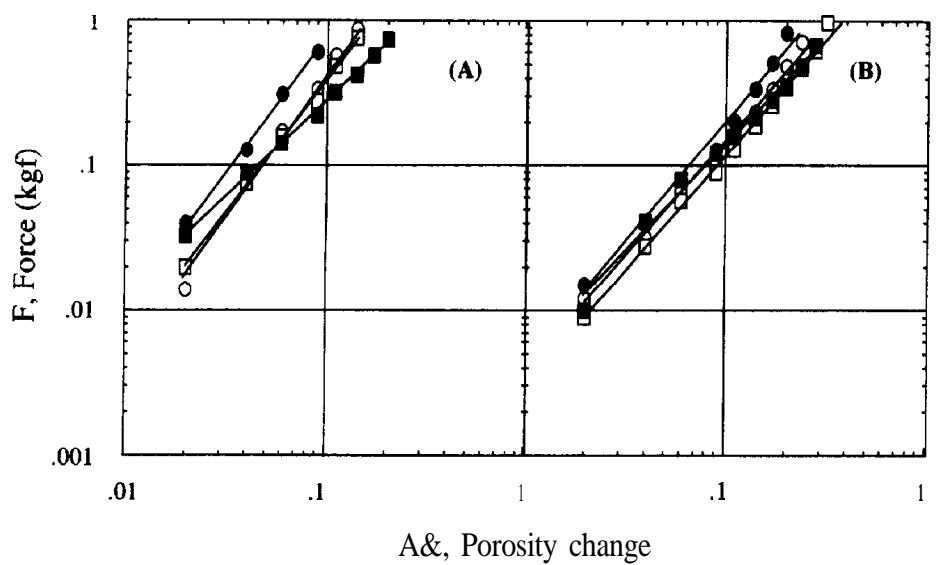

Fig. 3. Typical relation between force and porosity change of raw (A) and sterilized (B) soybeans fermented with Rhizopus oligosporus (TISTR3001) for different fermentation durations.

Symbols:@, control; $\bigcirc, 24$ h-fermentation; $\square, 36$ h-fermentation; $\square, 60$ hfermentation 


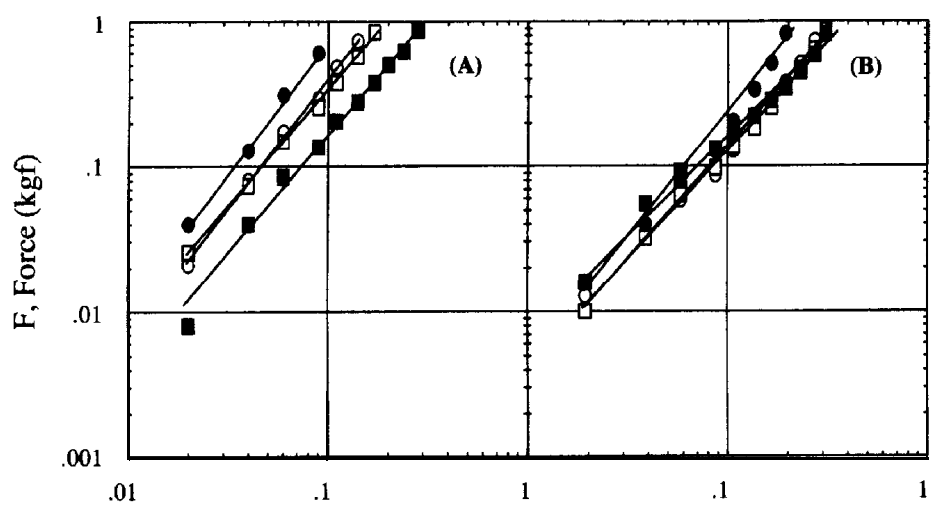

A\&, Porosity change

Fig. 4. Typical relation between force and porosity change of raw (A) and sterilized (B) soybeans fermented with Rhizopus sp. LKN for different fermentation durations.

Symbols are the same as those in Fig. 3.

Table 5. Summary of the n- and C-values obtained from the transformed curves of some Rhizopus strains used in this study.

Strain Rhizopus sp. LKN Rhizopus oligosporus Rhizopus sp. All Rhizopusjavanicus

\begin{tabular}{|c|c|c|c|c|c|c|c|c|c|c|c|c|c|c|c|c|c|}
\hline \multirow{2}{*}{\multicolumn{2}{|c|}{ time(h) }} & \multicolumn{16}{|c|}{ (TISTR3001) (IF05442) } \\
\hline & & 0 & 24 & 36 & 60 & 0 & 24 & 36 & 60 & 0 & 24 & 36 & 60 & 0 & 24 & 36 & 60 \\
\hline \multirow[t]{2}{*}{ raw } & n-value & 1.8 & 1.8 & 1.7 & 1.6 & 1.8 & 1.8 & 1.7 & 1.3 & 1.8 & 1.8 & 1.8 & 1.8 & 1.8 & 1.8 & 1.7 & 1.7 \\
\hline & $\mathrm{C}$-value & 50 & 25 & 8 & 13 & 50 & 25 & 50 & 6 & 50 & 50 & 40 & 40 & 50 & 40 & 25 & 13 \\
\hline \multirow[b]{2}{*}{ sterilized } & n-value & 1.7 & 1.5 & 1.5 & 1.3 & 1.7 & 1.6 & 1.6 & 1.5 & 1.7 & 1.7 & 1.7 & 1.7 & 1.7 & 1.6 & 1.6 & 1.6 \\
\hline & C-value & 10 & 4 & 4 & 3 & 10 & 6 & 5 & 4 & 10 & 10 & 8 & 7 & 10 & 10 & 5 & 4 \\
\hline
\end{tabular}

during fermentation which may soften soybean tissue. The n-value therefore may be an effective measure of soybean maceration, samples with $n>1.7$ considered hard; $n=1.5$, medium soft; and $\mathrm{n}<1.5$, soft. The $\mathrm{C}$-value, at intercept value on the $\mathrm{y}$-axis, depends on the starting point that is unstable measuring region and the $\mathrm{C}$-value is not significant in the relation describing the degree of maceration in the equation (1).

\section{DISCUSSION}

Hardness or softness for solid specimen has been defined as the force necessary to attain a given deformation (Szczesniak et al., 1963). Friedman et al. (1963) have developed their texturometer (General Food Texturometer) and the hardness was defined as the ratio of height of test specimen to a standard specimen. To compare the 
same texturometer with Instron texturometer (Bourne, 1968), Brennan et al. (1970) also reported on the textural properties of rubbers. By using the same texturometer, Kapsalis et al. (1970) determined the textural properties of pre-cooked, freeze dried beef and of special bite-size space foods in relation of its moisture content. Their definition of the hardness for solid specimen basically coincides with our definition of the degree of maceration, except bulk specimen tested. In case of the compressible solid-body, it is generally believed that the force-deformation relation is characterized by an equation, $\mathrm{F}=\mathrm{C}(\mathrm{D})^{\mathrm{n}}$. Based on the equation, we replaced the deformation term $\mathrm{D}$ with porosity change $\Delta \varepsilon$ in packing height for bulk specimen and modified the equation to $\mathrm{F}=\mathrm{C}(\Delta \varepsilon)^{\mathrm{n}}$. We determined this property by measuring the displacement of the bulk fermented soybean in the force-deformation curve at an arbitrarily selected maximum force. The maximum force of $1 \mathrm{kgf}$ selected in our study was such that the soybean specimen underwent significant deformation in specimen-height in the measuring-cell. Present modified equation is applicable to bulk specimen and the n-value may be interpreted as the degree of maceration of fermented bulk soybeans since the n-value may depend on the maceration capability of Rhizopus strains tested. Peleg and Campanella (1989) have reported on some experimental results on various soft solid-foods using compression test (by Instron UTM model 1000) in the process of the theoretical derivation for mechanical sensitivity of soft solid-foods. They discussed the n-value concerning only the concavity of force-deformation pattern. In case of our bulk specimen, a series of tests conducted on the soybean fermented by 7 varieties of Rhixopus strains revealed that the n-value, which is the degree of maceration, might represent the softness of fermented soybean depending on Rhizopus strain tested.

\section{REFERENCES}

Ariffin, R., C. Apostolopoulos, A. Graffham, D. MacDougall and D. J. Owens 1994 Assessment of hyphal binding in tempe. Letters in Applied Microbiology, 18: 32-34

Bourne, M. C. 1968 Texture profiling of ripening pears. J. Food Science, 32: 223-226

Brennan, J. G., R. Jowitt and 0. A. Mughsi 1970 Some experiences with the General Foods Texturometer. J. Texture Studies, $1: 167-184$

Friedman, H. H., J. C. Whitney and A. S. Szczesniak 1963 The Texturometer- a new instrument for objective texture measurement. J. Food Science, 28: 390-396

Hesseltine, C. W. 1965 A millennium of fungi, food, and fermentation. Mycologia, 57: 149-194

Hesseltine, C. W. and H. L. Wang 1967 Traditional fermented foods. Biotechnol. and Bioengin., 9: 275288

Kapsalis, J. G., B. Drake and B. Johannsen 1970 Textural properties of dehydrated foods. Relationship with the thermodynamics of water vapor sorption. J. Tetxure Studies, 1 : 285-308

Kronenberg, J. H. and D. Y. Hang 1985 A research note: Puncture testing method for monitoring solid substrate fermentation. J. Food Science, 50: 539-540

Nout, M. J. R. and F. M. Rombouts 1990 Recent developments in tempeh research. J. Appl. Bacteriol, 69: 609-633

Peleg, M. and 0. H. Campanella 1989 The mechanical sensitivity of soft compressible testing machines. $J$. Rheology, 33: 455-467

Steinkraus, K. H. 1986 Fermented foods, feeds, and beverages. Biotechnol. Advances, 4: 219-243

Szczesniak, A. S., M. A. Brandt and H. H. Friedman 1963 Development of standard rating scales for mechanical parameters of texture and correlation between the objective and the sensory methods of texture evaluation. J. Food Science, 28: 397-403 